\title{
INFLUÊNCIA DA BIOMECÂNICA ANGULAR DAS ARTICULAÇÕES ESCÁPULO- UMERAL, COXO-FEMURAL E TÍBIO-METATARSIANA NA PROVA DE ANDAMENTO DOS CAVALOS DA RAÇA CRIOULA
}

\author{
Carlos Anselmo dos Santos ${ }^{1}$, Cahuê Francisco Rosa Paz ${ }^{1}$, Júlio Cesár \\ Paganela ${ }^{1}$, Pedro Kustcher Ripoll ${ }^{1}$, Carlos Eduardo Wayne Nogueira ${ }^{1}$ \\ 1 Universidade Federal de Pelotas - cahuepaz@gmail.com
}

\begin{abstract}
RESUMO: Considerando o cavalo Crioulo um cavalo de sela, as medidas angulares dos eixos ósseos das principais articulações envolvidas na dinâmica do movimento devem ser avaliadas para melhor caracterização do padrão racial. Objetivou-se com o presente estudo estabelecer uma relação dos ângulos das articulações escápulo-umeral, coxo-femural e tíbio-metatarsiana, com o desempenho desses animais na prova de andamento, relacionando assim diretamente ângulos e notas. Foram avaliados 74 equinos que participaram das Classificatórias do Freio de Ouro, as medidas aferidas foram: ângulo da escápula com o solo, ângulo do íleo com o solo e ângulo tíbiometatársico. A articulação que manteve correlação positiva de influência em todas as etapas da prova foi à articulação escápulo-umeral. Os animais que obtiveram as melhores notas em média foram os que apresentaram ângulo menor que $53^{\circ}$ para a articulação escápulo-umeral. Já as articulações coxo-femural e tíbio-metatársica demonstraram uma grande variação de resultado durante a prova.
\end{abstract}

Palavras-chave: conformação; competição; equino; freio de ouro

\section{INFLUENCE OF THE SCAPULA-HUMERUS ANGLE, COXO-FEMURS AND TIBIO-III- METATARSAL ANGLE IN GAIT PROOF OF CRIOULO HORSES}

\begin{abstract}
Considering the Crioulo a saddle horse, the angular measures of the bone axles of the principal articulations wrapped in the dynamic one of the movement must be valued for better characterization of the racial standard. The objective by the present study to establish a relation of the angles of the articulations scapular-humeral, lame-femoral and tibio-metartarsal, with the performance of these animals in the proof of gait, making a list so straightly of angles and notes. There were valued 74 equine ones that participated of the Qualifying ones of the Golden brake, the checked measures were: angle of the hook with the ground, angle of the ileum with the ground and tibio-metatarsal angle. The relationship that has kept a positive correlation of influence in all stages of the race was the scapular-humeral joint. Animals that received the best grades in those who had averaged less than $53^{\circ}$ angle to the scapular-humer al joint. The articulation that maintained positive correlation of influence in all stages of the proof is the articulations scapular-humeral. Already the articulations lame-femoral and tibio-metartasal demonstrated a great variation of result during the competition.
\end{abstract}

Key Words: conformation; competition; equine; freio de ouro 


\section{INTRODUÇÃO}

A conformação de um cavalo é a chave para seu método de progressão, considerando o cavalo Crioulo um cavalo de sela, que deve desempenhar movimentos cômodos e progressivos. As medidas angulares dos eixos ósseos, das principais articulações envolvidas na dinâmica do movimento, devem ser avaliadas para melhor caracterização do padrão racial e entendimento das principais lesões locomotoras da raça. A prova de andamento é exigente pelo fato de acionar de modo complexo todos os músculos do animal o que permite apreciar a amplitude e a coordenação de seus movimentos. Nesta prova é avaliada sua definição, manutenção, comodidade, naturalidade, tipicidade, qualidade e progressão.

O estudo buscou verificar a ação da biomecânica angular dos membros em relação aos diferentes tipos de andamento (passo, trote e galope) e estabelecer uma possível tendência da ação dos ângulos escápulo-umeral, coxo-femural e tíbio-metatársicos no desempenho desses animais na prova de andamento da raça crioula.

\section{MATERIAL E MÉTODOS}

Foi realizado estudo descritivo e transversal que incluiu 74 equinos, com idade entre 5 e 15 anos, que participaram das Classificatórias do Freio de Ouro de 2008, nas cidades de Bagé e Pelotas, no Rio Grande do Sul. Todos os equinos se apresentavam clinicamente sadios e o tipo de prova escolhido para realizar o estudo foi a de andamento, pois esta é a que sofre menor interferência de fatores externos, como por exemplo: temperamento do animal, ginete, bovinos, tipo de pista, entre outros.

Os animais estavam posicionados em apoio quadrupedal, foram avaliados em superfície plana, estando os quatro membros alinhados, e as medidas aferidas foram os ângulos da escápula com o solo (A), do íleo com o solo (B) e o tíbio-metatársico (C). Para aferir estes ângulos foi usado um artrogoniômetro.

Depois de realizar todas as aferições e determinar quais eram as médias de cada medida, os cavalos analisados foram divididos em três grupos de animais: a média da raça, os de maiores angulações e de menores angulações nas três articulações avaliadas. Classificados de acordo com a angulosidade em $<53^{\circ}$ graus, entre $53^{\circ}$ e $60^{\circ}$ graus e $>60^{\circ}$ graus para a articulação escápulo-umeral; < 19을 entre $19^{\circ}$ e $21^{\circ}$ e $>21^{\circ}$ graus para articulação coxo-femural e em relação à articulação tíbio-metatarsiana em < $148^{\circ}$, entre $148^{\circ}$ e $152^{\circ}$ e $>152^{\circ}$ graus. Assim facilitando o entendimento do padrão racial através da média das angulações e possibilitando a avaliação de quais grupos de angulações teriam melhor desempenho nas três fases da prova. Como variáveis dependentes para o presente estudo foram usadas as notas da prova de andamento, na marcha inicial ao passo com apoio tripedal ou tranco, no trote e no galope. Cada animal durante o processo de julgamento recebia uma nota especifica para estas três atividades que foram registrados para posterior análise. Os animais que eram penalizados durante a prova não foram incluídos no estudo. Todas as angulações foram analisadas como variáveis contínuas e também como variáveis categóricas ordinais utilizando diferentes pontos de corte para cada uma delas usando regressão linear e ANOVA respectivamente. Os testes estatísticos usados nas análises foram o teste de Wald na regressão linear e o teste $F$ para o ANOVA Stata 9.0. (Ayres et al, 2007). 
Tabela 1 - Notas no tranco, trote e galope conforme diferentes categorias nos ângulos escápuloumeral, coxo-femural e tíbio-metatársico na prova de andamento dos cavalos da raça Crioula

\begin{tabular}{lccccccc}
\hline \multirow{2}{*}{ Ângulos } & \multicolumn{2}{c}{ Tranco } & \multicolumn{2}{c}{ Trote } & \multicolumn{2}{c}{ Galope } \\
\cline { 3 - 7 } & $\mathrm{N}$ & Média (DP) & Valor $\mathrm{p}^{*}$ & Média (DP) & Valor $\mathrm{p}^{*}$ & Média (DP) & Valor $\mathrm{p}^{*}$ \\
\hline Escápulo-umeral & & & & & & & \\
$\quad<53$ & 7 & $7,0(0,6)$ & 0,3 & $6,7(1,3)$ & 0,7 & $7,2(1,4)$ & 0,1 \\
$53-60$ & 45 & $6,6(1,7)$ & & $6,5(0,9)$ & & $6,8(0,9)$ & \\
$\quad>60$ & 22 & $6,4(1,1)$ & & $6,7(1,0)$ & & $6,5(1,2)$ & \\
Coxo-femural & & & & & & & \\
$\quad<18$ & 14 & $6,6(2,3)$ & 1,0 & $6,6(0,8)$ & 0,9 & $7,2(0,8)$ & 0,4 \\
$18-24$ & 55 & $6,6(1,2)$ & & $6,5(1,0)$ & & $6,6(1,0)$ & \\
$>24$ & 5 & $6,6(0,5)$ & & $6,8(1,1)$ & & $7,3(1,5)$ & \\
Tíbio-metatársico & & & & & & & \\
$<147$ & 20 & $6,8(1,3)$ & 1,0 & $6,4(1,1)$ & 0,9 & $6,8(1,1)$ & 0,9 \\
$147-153$ & 36 & $6,4(1,7)$ & & $6,7(0,9)$ & & $6,7(1,0)$ & \\
$>153$ & 18 & $6,8(0,9)$ & & $6,4(1,0)$ & & $6,8(1,0)$ & \\
Total & 74 & $6,6(1,4)$ & & $6,6(1,0)$ & & $6,8(1,0)$ & \\
\hline
\end{tabular}

${ }^{*}$ Teste $\mathrm{F}$ de ANOVA. $\mathrm{P}<0,01$.

\section{RESULTADOS}

As médias de notas no tranco e no trote para os 74 equinos avaliados foram de 6,6 em ambos os casos (DP 1,4 e 1,0 respectivamente), enquanto que para o galope a média foi de 6,8 (DP 1,0).

A Tabela 1 apresenta as médias de nota no tranco, no trote e no galope conforme diferentes categorias nos ângulos escápulo-umeral, coxo-femural e tíbio-metatársico. Houve uma aparente relação inversa entre o ângulo escápulo-umeral e as notas de tranco e galope, mas esta diferença não foi estatisticamente significativa $(P=0,3$ e 0,1 , respectivamente).

Não houve nenhuma relação entre as outras duas articulações com as diferentes médias de nota obtidas pelos equinos. Ao analisar as angulações categorizadas em subdivisões (Tabela 2) também não houve nenhuma associação significativa.

A regressão linear (Tabela 3) mostrou também uma tendência inversa entre o ângulo escápulo-umeral e as notas de tranco e galope ( $\beta-0,04$ e 0,03 respectivamente), mas novamente estas associações não foram estatisticamente significativas $(P=0,3$ em ambos os casos).

\section{DISCUSSÃO}

O tranco é um andar de quatro tempos, independente da forma em que é realizado. Cada tempo é dado quando o casco pousa no chão. Em geral a marcha se inicia por um membro anterior, e a sucessão de apoio é desta maneira: MAD, MPE, MAE, MPD, ocorrendo de forma cadenciada, e constante. Porém nas fases de apoio e suspensão, a duração de cada uma deve ser igual (Funtanillas, 2004). Nesta marcha não existe momento de suspensão e há sempre dois ou três membros apoiados no chão. O ângulo escápulo-umeral incide de forma direta no comprimento do passo.

Em relação ao ângulo escápuloumeral os animais que obtiveram as melhores notas em média foram os que apresentaram ângulo menor que 53\%, com 7,2 de pontuação, os animais que tiveram ângulo acima de $60^{\circ}$ obtiveram em média 6,3 de pontuação, entretanto não foi observado diferença estatística.

Confirmando assim a hipótese de Stashak (2006) que cavalos com uma escápula mais horizontal ou uma articulação do ombro mais flexionada demonstram extensão máxima da articulação do cotovelo em relação ao ângulo no contato inicial com o chão. 
Tabela 2 - Média de notas no tranco, trote e galope conforme subdivisões dos ângulos escápuloumeral, coxo-femural e tíbio-metatársico na prova de andamento dos cavalos da raça Crioula

\begin{tabular}{|c|c|c|c|c|c|c|c|}
\hline \multirow[b]{2}{*}{ Ângulos } & \multirow[b]{2}{*}{$\mathrm{N}$} & \multicolumn{2}{|c|}{ Tranco } & \multicolumn{2}{|c|}{ Trote } & \multicolumn{2}{|c|}{ Galope } \\
\hline & & $\begin{array}{l}\text { Média } \\
\text { (DP) }\end{array}$ & Valor $p^{*}$ & $\begin{array}{l}\text { Média } \\
\text { (DP) }\end{array}$ & Valor $p^{*}$ & $\begin{array}{l}\text { Média } \\
\text { (DP) }\end{array}$ & Valor $\mathrm{p}^{*}$ \\
\hline \multicolumn{8}{|l|}{ Escápulo-umeral } \\
\hline$<57$ (tercil inferior) & 26 & $6,5(1,9)$ & 0,8 & $6,5(1,0)$ & 0,5 & $6,8(1,1)$ & 0,5 \\
\hline $57-60$ & 26 & $6,7(1,2)$ & & $6,5(0,9)$ & & $7,0(0,8)$ & \\
\hline$>60$ (tercil superior) & 22 & $6,4(1,1)$ & & $6,7(1,0)$ & & $6,5(1,2)$ & \\
\hline \multicolumn{8}{|l|}{ Coxo-femural } \\
\hline$<19$ (tercil inferior) & 26 & $6,6(1,8)$ & 0,4 & $6,6(0,8)$ & 1,0 & $6,8(1,0)$ & 0,6 \\
\hline $19-21$ & 36 & $6,3(1,3)$ & & $6,5(1,0)$ & & $6,5(1,0)$ & \\
\hline$>21$ (tercil superior) & 15 & $7,1(0,8)$ & & $6,6(1,2)$ & & $7,3(1,5)$ & \\
\hline \multicolumn{8}{|l|}{ Tíbio-metatársico } \\
\hline$<148$ (tercil inferior) & 31 & $6,6(1,4)$ & 0,7 & $6,5(1,1)$ & 0,7 & $6,8(1,0)$ & 0,9 \\
\hline $148-152$ & 22 & $6,2(1,8)$ & & $6,8(0,9)$ & & $6,7(1,2)$ & \\
\hline$>152$ (tercil & 21 & $6,9(1,0)$ & & $6,4(0,9)$ & & $6,8(0,9)$ & \\
\hline superior) & 74 & $66(14)$ & & $66(10)$ & & $68(10)$ & \\
\hline
\end{tabular}

Tabela 3 - Coeficientes de regressão das notas no tranco, trote e galope conforme ângulos escápuloumeral, coxo-femural e tíbio-metatársico na prova de andamento dos cavalos da raça Crioula

\begin{tabular}{|c|c|c|c|c|c|c|}
\hline & Tranco & & Trote & & Galope & \\
\hline Ângulos & $\beta$ (IC95\%) & Valor $\mathrm{p}^{*}$ & $\beta$ (IC95\%) & Valor $\mathrm{p}^{*}$ & $\beta$ (IC95\%) & Valor $\mathrm{p}^{*}$ \\
\hline Escápulo-umeral & $\begin{array}{c}-0,04 \\
(-0,12 ; 0,04)\end{array}$ & $0,3 b$ & $\begin{array}{c}0,01 \\
(-0,04 ; 0,07)\end{array}$ & 0,6 & $\begin{array}{c}-0,03 \\
(-0,09 ; 0,03)\end{array}$ & 0,3 \\
\hline Coxo-femural & $\begin{array}{c}0,00 \\
(-0,11 ; 0,12)\end{array}$ & 1,0 & $\begin{array}{c}0,01 \\
(-0,07 ; 0,08)\end{array}$ & 0,9 & $\begin{array}{c}-0,01 \\
(-0,09 ; 0,08)\end{array}$ & 0,9 \\
\hline Tíbio-metatársico & $\begin{array}{c}0,01 \\
(-0,05 ; 0,07)\end{array}$ & 0,7 & $\begin{array}{c}-0,01 \\
(-0,05 ; 0,03)\end{array}$ & 0,6 & $\begin{array}{c}-0,01 \\
(0,06 ; 0,03)\end{array}$ & 0,5 \\
\hline
\end{tabular}

$\beta$ - coeficientes de regressão linear

* Teste de Wald

Isso prolonga a fase de contato com o solo, desta forma produzindo um tranco com melhor avanço e maior comodidade.

Para Monina (2006) um ângulo de $45^{\circ}$, o comprimento do passo é igual à altura do animal. À medida que o ângulo aumenta diminui a amplitude e rendimento da marcha e ângulos acima de $55^{\circ}$ reduzem em $25 \%$ a longitude em relação aos de $45^{\circ}$. Pode-se observar no presente trabalho, que animais com ângulos maiores que $53^{\circ}$ obtiveram notas mais baixas devido a essa diminuição da amplitude e rendimento da marcha.

As maiores notas de tranco quando relacionadas com a articulação coxo-femural, foram as dos cavalos com maiores angulações de garupa, ou seja, animais com garupas mais verticais.

A angulação tíbio-metatarsiana, assim como a coxo-femural demonstraram que cavalos com ângulos de jarretes mais retos mantêm uma tendência de melhores notas de tranco em relação aos demais ângulos.

O tranco por ser um andamento mais lento e menos elevado, sem fase de suspensão, teria menor influência da angulação coxo-femural e tíbiometatársica porque é um andamento de passadas mais horizontais. Provavelmente esta hipótese explica-se porque as melhores notas de trote são as dos animais com ângulos mais horizontais de coxo-femural e tíbiometatarsiana, pois no trote 0 que 
predomina são movimentos de suspensão.

Segundo Funtanillas (2004) no tranco, cabeça e pescoço se relacionam com os membros posteriores através da inércia de impulsão que estes transmitem através da coluna vertebral, compensado pelo centro de gravidade para frente durante a marcha. Esta afirmação é evidenciada com os resultados obtidos neste estudo com a raça Crioula, relacionando-se o ângulo escápulo-umeral onde apresentou-se as melhores notas durante o tranco.

O trote é um andamento natural, simétrico, de dois tempos e saltado. É simétrico porque a ação de cada diagonal se repete em cada ciclo (MAE, MPD, MAD E MPE). Os dois tempos estão dispostos por sucessivos apoios de cada diagonal com o terreno, separados pelo tempo de suspensão, razão esta que justifica a qualidade do trote. Nesta fase os membros que geram impulsão se contraem e se encurtam, assim à força de gravidade fará atuação no pouso do corpo pelo terreno, com extensão progressiva das articulações da diagonal oposta. Quanto mais prolongado for 0 tempo de suspensão, mais largo será o trote (Funtanillas, 2004). Neste andamento o animal mantém um momento de suspensão absoluta no ar pelos quatro membros (Monina, 2006).

O resultado da avaliação estatística não demonstrou diferença significativa entre os menores, a média e os maiores ângulos, entretanto não diferiu do tranco em relação à articulação escápulo-umeral, visto que os animais com menores ângulos $(<539$ foram os que obtiveram as melhores notas, associando-se assim a conclusão de Larrouse (2006), na qual cita que a melhor combinação em termos de espádua é uma escápula naturalmente inclinada, que forme um ângulo relativamente fechado com um úmero curto. E segundo Stashak (2006), uma conformação de escápulo-umeral mais reta resulta em um andamento curto e picado, o qual não é desejável para raça Crioula, pelo fato de ser avaliada a comodidade durante o movimento.

A articulação coxo-femural indica variação quando comparada com sua função no tranco, visto que no trote os animais com as melhores notas foram os de menores ângulos de coxofemural. Segundo Larrouse (2006) a bacia inclinada é encontrada nos cavalos de corrida do tipo quarto de milha, onde uma bacia mais horizontal oferece uma amplitude melhor de passada.

Os animais com ângulo tíbiometatársico menores foram os que tiveram o melhor desempenho, e mantiveram a mesma contrariedade da articulação coxo-femural em relação ao tranco, pois os animais com ângulos mais retos de jarrete foram os com melhor tranco e os com ângulos mais horizontais se destacaram no trote. As melhores notas de trote foram acompanhadas por ângulos menores, pois no trote a intensidade de impulsão e suspensão são maiores que no tranco, portanto indo de encontro à afirmação de Funtanillas (2004), em que a correta função da articulação coxal e társica e favorecer a ação natural dos membros posteriores para a impulsão do corpo do cavalo. Esse tipo de resultado é mantido pelo tipo de movimento que cada andamento desenvolve durante a locomoção.

O galope é um andamento natural, assimétrico e saltado, sendo um movimento de três tempos que se transformam em quatro somente no galope de carreira. O galope é uma série de saltos sem interrupção, neste andamento o cavalo alterna o apoio uni, bi ou tripedal com períodos de suspensão no ar (Funtanillas, 2004).

No galope assim como no tranco e no trote os animais com ângulo escápulo-umeral mais horizontal foram 
os que apresentaram as melhores notas, mesmo não existindo significância estatística concluindo assim que o ângulo escápulo-umeral mantém a mesma tendência em ambos os andamentos. Resultados esses que acompanham outras modalidades equestres, pois Stashak (2006), em seu estudo com cavalos de salto e adestramento concluiu que equinos com escápula mais horizontal tiveram os melhores resultados nessas modalidades.

Os resultados obtidos com a articulação coxo-femural assemelhamse com os obtidos com essa articulação no tranco, onde os cavalos com maior angulação de garupa demonstraram melhores notas que os demais. Segundo Larrouse (2006) cavalos com jarretes mais retos, geralmente acompanham garupas mais anguladas, sendo assim obtendo uma facilidade maior em empregar os posteriores embaixo do corpo por uma questão de biodinâmica de movimento. Por outro lado são cavalos em que mantêm sua musculatura coxal e lombar em constante stress.

Os animais com menores angulações de jarrete tiveram as melhores notas, seguindo assim a mesma linha do trote, porem diferentemente ao resultado obtido nessa articulação em relação ao tranco. Tais resultados se justificam pelo tipo de movimento realizado em cada andamento, nas quais o trote e o galope se assemelham mais em movimentos e resultados quando comparadas ao tranco.

Os resultados obtidos na raça Crioula mostraram-se contrários a outros estudos, visto que Back et al. (1996) relataram que articulações mais retas de jarrete estavam relacionadas a maiores passadas e maior duração de suspensão e, também, a maior extensão da movimentação do tarso. No presente trabalho os animais com menores angulações de jarrete foram os que apresentaram as melhores notas de galope, mas é necessário ressaltar que na raça crioula também é avaliado no galope, sua comodidade, na qual se acredita que cavalos com angulações de jarretes mais retas tenham pior cômodo.

Para Stashak (2006), membros posteriores verticalizados apresentam menor comprimento geral e produzem movimentos eficientes, adequados para cavalos de caça e de corrida. Em geral cavalos com ângulos menores apresentam um comprimento maior $\mathrm{e}$ estão geralmente associados a uma conformação de acampado ou de jarretes em foice. O relacionamento do comprimento dos ossos, os ângulos das articulações e a altura total dos membros posteriores indicarão o tipo de ação e a quantidade de energia produzida.

\section{CONCLUSÃO}

Há uma tendência de influência da biomecânica das articulações escápuloumeral, coxo-femural e tíbio-metatarsiana no desempenho dos animais na prova de andamento, variando a intensidade de influência de cada articulação conforme 0 andamento (tranco, trote e galope) que está sendo executada em cavalos da raça Crioula.

\section{REFERÊNCIAS}

AYRES, M.; AYRES JUNIOR, M.; AYRES, D. L. et al. BioEstat: aplicações estatísticas nas áreas de ciências biomédicas. Belém - PA, 2007. $334 \mathrm{p}$

ASSOCIAÇÃO BRASILEIRA DE CRIADORES DE CAVALOS CRIOULOS (ABCCC); História da Raça Crioula. Disponível em:

$<$ http://www.abccc.com.br/historico.php?e_p=11 >. Acesso em: 12/07/08.

BACK, W.; CLAYTON, H.M. Equine

Iocomotion. London: W.B. Saunders, 2001. $135 p$. 
FUNTANILLAS, H.A. Elementos de podologia equina y herrado corretivo. Buenos Aires:

Hemisfério Sur, 2004. p.103-119.

LAROUSSE DOS CAVALOS. Larousse du cheval. São Paulo: Larousse do Brasil, 2006. p.58-65.
MONINA, I. Biomecánica equina In: BOFFI, F.M.; Fisiologia del ejercicio en equinos. 1.ed. Buenos Aires: Inter-Médica, 2006. p.177-195.

STASHAK, T.S. Relação entre conformação e claudicação. Claudicação em Equinos segundo Adams. 4.ed. São Paulo: Roca, 2006. p.55-77. 